\title{
Intra-Articular Enzyme Administration for Joint Disease in Feline Mucopolysaccharidosis VI: Enzyme Dose and Interval
}

\author{
DYANE AUCLAIR, LEANNE K. HEIN, JOHN J. HOPWOOD, AND SHARON BYERS
}

Lysosomal Diseases Research Unit [D.A., J.K.H., J.J.H.], Matrix Biology Unit [S.B.], Department of Genetic Medicine, Children, Youth and Women's Health Service, North Adelaide, SA 5006, Australia; Department of Paediatrics [J.J.H., S.B.], The University of Adelaide,

Adelaide, SA 5000, Australia

\begin{abstract}
Degenerative joint changes have been reported in human mucopolysaccharidosis VI (MPS VI) and are a prominent feature of feline MPS VI. Joint disease has proven refractory to intravenous enzyme replacement therapy (ERT) in the MPS VI cat because enzyme is unable to reach cells in cartilage. In this study, enzyme was infused directly into the intraarticular space to determine whether joint tissues are able to respond to replacement enzyme. Clearance of glycosaminoglycans from chondrocytes was observed at a dose of $10 \mu \mathrm{g}$ recombinant human $N$-acetylgalactosamine-4sulfatase (rh4S), but greater clearance was observed with higher doses. The chondrocytes at the articular surface were cleared preferentially. Lysosomal vacuolation in cruciate ligament and synovial cells also decreased upon addition of rh4S. One month after injection of $\mathrm{rh} 4 \mathrm{~S}$, a slight reaccumulation of storage was observed at the surface of the joint, but extensive reaccumulation was observed 2 mo after injection. These results indicate that by bypassing the synovium using intraarticular ERT, significant reduction in storage material in joint tissues can be achieved. Localized ERT in the joint space provides a mechanism for delivering enzyme directly to the articular cartilage and a potential therapy for joint pathology in MPS VI. (Pediatr Res 59: 538-543, 2006)
\end{abstract}

$\mathrm{M}^{\mathrm{p}}$ PS VI (Maroteaux-Lamy Syndrome) is a lysosomal storage disorder (LSD) that occurs secondary to a major reduction or complete loss of $\mathrm{N}$-acetylgalactosamine-4sulfatase (4S, EC 3.1.6.1) activity. $4 \mathrm{~S}$ activity is required for the catabolism of chondroitin sulphate (CS) and dermatan sulphate (DS) glycosaminoglycans (GAG). An inadequate level of $4 \mathrm{~S}$ results in the accumulation of CS and DS within lysosomes, causing lysosomal engorgement, cell enlargement, and dysfunction (1).

Wide phenotypic variations have been described in human MPS VI. The cardinal clinical features of the severe MPS VI phenotype are characterized by major skeletal abnormalities (short stature, dysostosis multiplex) and restriction in joint movements (most likely due to thickened joint capsules and epiphyseal deformities). Other features include cardiomyopathy and valvular dysfunction, upper airway obstruction, coarse facies, corneal clouding, and hepatosplenomegaly (1-3). Ar-

Received July 12, 2005; accepted November 21, 2005.

Correspondence: Sharon Byers, Ph.D., Matrix Biology Unit, Department of Genetic Medicine, Children, Youth and Women's Health Service, 72 King William Rd., Nth Adelaide, SA 5006, Australia; e-mail: sharon.byers@adelaide.edu.au

This study was supported by grants from The National Health and Medical Research Council of Australia and BioMarin Pharmaceutical Inc.

DOI: 10.1203/01.pdr.0000203090.41012.a6 thritic lesions have been recorded at autopsy of a $27-y$-old MPS VI patient (4).

The feline MPS VI model closely mimics the human disease. A variety of gross pathologic lesions indicative of DJD are commonly encountered in the joints of MPS VI cats older than 6 mo of age $(5,6)$. In younger MPS VI cats $(12-15$ wk of age; open physes), radiographs of joints indicate irregular subchondral bone contour and increased joint space $(5,7,8)$. Vacuolation of chondrocytes is the most striking histologic feature of cartilage samples obtained from MPS VI cats at various ages $(9,10)$ and is already present in the mid-term fetus (5). DJD has a complex etiology that is compounded in MPS VI by the underlying genetic abnormality. Although the exact pathophysiology of DJD is not well understood, possible underlying pathogenic mechanisms for the development of DJD in MPS VI animals are starting to emerge $(11,12)$. Once initiated, DJD is difficult to reverse and it affects all tissues in the joint. Therefore, therapy for MPS VI should target chondrocytes, synoviocytes, osteoblasts, osteoclasts, osteocytes, and ligament cells.

Until recently, the only specific therapy available for MPS VI children was bone marrow transplantation (BMT) $(13,14)$. Apart from the obvious problems associated with BMT (e.g. lack of suitable donor; high mortality/morbidity), no noticeable change in bone pathology has been reported in the few MPS VI patients that received BMT, although some improvement in joint mobility occurred (14).

During the last 4-5 y, human clinical trials using systemic enzyme replacement therapy (ERT) with rh4S have been carried out in Australia and the United States (15). Although the human trials have not been undertaken for a sufficient length of time to determine joint response, all results obtained to date in the MPS VI cat indicate that intravenous ERT is unable to deliver sufficient corrective enzyme to articular cartilage to significantly affect the pathology in this tissue and alter joint disease (5). The lack of improvement seen in the cartilage is generally attributed to the avascular nature of this

Abbreviations: CS, chondroitin sulphate; DJD, degenerative joint disease; DS, dermatan sulphate; ERT, enzyme replacement therapy; GAG, glycosaminoglycan; IA INJ, intraarticular injection; MPS VI, mucopolysaccharidosis VI; rh4S, recombinant human $N$-acetylgalactosamine-4-sulfatase 
tissue. Fortunately, bone cells respond well to systemic ERT and improvement in bone mass and shape is observed $(5,16,17)$.

Because evidence is accumulating to suggest that a unimodal therapeutic approach (e.g. intravenous ERT) is not sufficient to achieve maximal effects in all tissues, designing a multimodal approach, including direct application of enzyme into joint spaces, seems a logical step. In the present study, we postulate that by raising the intraarticular concentration of rh4S to therapeutic levels in the joint space, improvement in GAG storage and chondrocyte vacuolation will occur. Our first aim was to assess whether high amounts of enzyme could affect GAG storage in vitro. Thereafter, we determined the intraarticular dose of rh4S required to remove undegraded GAG from MPS VI cartilage cells and estimated the amount of time before reaccumulation of lysosomal storage following a single IA INJ of rh4S. Finally we tested whether repeated IA INJ of rh4S would be beneficial to cartilage.

\section{METHODS}

In vitro correction of storage. Rib cartilage was removed from MPS VI animals and dissected clear of adherent muscle and perichondrium. Cartilage was minced finely and placed into organ culture in Dulbecco's modified Eagle's medium supplemented with $10 \%$ fetal calf serum, 50 units penicillin, and $50 \mu \mathrm{g} / \mathrm{mL}$ streptomycin sulphate. rh $4 \mathrm{~S}$ was added to a final concentration of $0.5,5.0$, or $50 \mu \mathrm{g} / \mathrm{mL}$ of medium. Tissue was incubated for $2 \mathrm{~d}$, the medium renewed, and tissue incubated for a further $2 \mathrm{~d}$. On $\mathrm{d} 4$, the medium was removed and the tissue fixed in $2 \%$ ( $\mathrm{vol} / \mathrm{vol}$ ) glutaraldehyde, $2 \%$ ( $\mathrm{vol} / \mathrm{vol}$ ) paraformaldehyde, and $0.7 \%(\mathrm{wt} / \mathrm{vol})$ ruthenium hexamine trichloride in 0.1 $\mathrm{M}$ cacodylate buffer ( $\mathrm{pH}$ 7.2) and processed for transmission electron microscopy (TEM).

Enzyme preparation. Both rh $4 \mathrm{~S}$ and recombinant feline N-acetylgalactosamine 4-sulfatase (rf4S) were used, and both were derived from stably transfected Chinese hamster ovary cell lines expressing the appropriate enzyme. rf $4 \mathrm{~S}$ was purified from cell culture medium using an antibody affinity purification column as previously described (18). rh4S preparations were produced and provided by BioMarin Pharmaceutical Inc. (Novato, CA). All preparations were formulated as sterile solutions containing $1 \mathrm{mg} / \mathrm{mL}$ of $\mathrm{rh} 4 \mathrm{~S}$ at pH 5.8 in $10 \mathrm{mM}$ sodium phosphate and $150 \mathrm{mM}$ sodium chloride (with or without polysorbate 80 ). The activity of $\mathrm{rh} 4 \mathrm{~S}$ was determined using a fluorogenic assay as described previously (19), protein concentration was determined using Bio-Rad dye reagent concentrate (Bio-Rad Laboratories,
Pty., Ltd, NSW, Australia) (20), and purity was assessed by SDS-PAGE. If required for IA INJ, enzyme was concentrated to yield a final concentration of $\sim 5 \mathrm{mg} / \mathrm{mL}$ suitable for injection in a small volume. Enzyme was concentrated in an Amicon filtration unit using a YM-10 membrane (cut-off $=$ $10,000 \mathrm{Da})$ and sterile filtered.

Test animals. Cats were bred and maintained at the Institute of Medical and Veterinary Science, Adelaide, South Australia. Animal husbandry has been previously described $(5,17)$. Studies were approved by the Women's and Children's Hospital and Institute of Medical and Veterinary Science Animal Ethics Committees.

MPS VI diagnosis and genotypes. Air-dried blood films from newborn kittens were stained with May-Grunwald Giemsa and examined for changes in white cell morphology characteristic of MPS VI (5). Genotype (L476P homozygotes) was subsequently confirmed by PCR analysis (18). This genotype results in a severe clinical MPS VI phenotype associated with a very low level of feline $4 \mathrm{~S}$ protein.

Experimental outline. A single dose of 10, 100, or $500 \mu \mathrm{g} \operatorname{rf} 4 \mathrm{~S}(70 \mu \mathrm{L}$ volume) was injected into the right knee joint of 2-mo-old MPS VI cats $(n=$ 1 per dose). Animals were killed $7 \mathrm{~d}$ after injection. A single dose containing 10,100 , or $500 \mu \mathrm{g}$ of rh $4 \mathrm{~S}$ protein per $70 \mu \mathrm{L}$ was injected at $1-2$ mo of age (range, 36-64 d of age) into the joint cavities of the right shoulders, elbows and knees of six cats. The contralateral joints (left shoulders, elbows, and knees) of all but one cat were treated with $70 \mu \mathrm{L}$ of phosphate buffer $(10 \mathrm{mM}$ sodium phosphate, $150 \mathrm{mM}$ sodium chloride, $\mathrm{pH}$ 5.7). The contralateral joints of the remaining cat received $1 \mu \mathrm{g}$ of rh $4 \mathrm{~S}$ protein per $70 \mu \mathrm{L}$. Cats were killed $7(n=3), 28(n=1), 56(n=1)$, or $86 \mathrm{~d}(n=1)$ after therapy.

In one additional cat, a dose containing $500 \mu \mathrm{g}$ of rh $4 \mathrm{~S}$ protein per $70 \mu \mathrm{L}$ was administered at $64 \mathrm{~d}$ of age into the right shoulder, elbow, and knee joints followed by a second dose of enzyme 4 mo later (176 d of age). On both occasions, the contralateral joints were injected with $70 \mu \mathrm{L}$ of buffer. This cat was killed $7 \mathrm{~d}$ after the second injections (Table 1).

All IA INJ were administered under general anesthesia. Immediately before injection, the skin covering each joint was clipped and disinfected. Recombinant enzyme or buffer was injected using a 0.5 -mL tuberculin syringe and 29-gauge needle. Immediately after injection, the joint was flexed and extended gently to allow for an even distribution of fluid throughout the joint cavity. Cats were monitored during and after IA INJ for signs of anaphylaxis or hypersensitivity reactions. An overdose of barbiturate was used for euthanasia.

Sample collection, histology, and cytology. Synovium samples from all joints were collected into $10 \%$ ( $\mathrm{vol} / \mathrm{vol}$ ) formalin for histologic examination by light microscopy. Sections were stained with hematoxylin and eosin and examined for synovial hyperplasia, vacuolation of synovial cells, and signs of inflammation. A smear of synovial fluid was stained with May-Grunwald Giemsa for cytological evaluation. Cartilage samples were collected at "standardized" sites (the medial tibial condyle, the lateral humeral condyle, craniodistal to the intertubular groove on the humeral head) where thickness is relatively even and where abnormalities develop in older MPS VI cats. Cartilage samples were fixed in $2 \%$ (vol/vol) glutaraldehyde/2\% (vol/vol)

Table 1. General information for the cats included in this study and dose of rh4S injected into their joints

\begin{tabular}{|c|c|c|c|c|c|c|c|}
\hline CAT ID & \multicolumn{6}{|c|}{ Single treatment* } & $\begin{array}{c}\text { Repeated treatment** } \\
7 \mathrm{f}\end{array}$ \\
\hline Sex & Male & Male & Male & Female & Female & Female & Female \\
\hline Age at treatment $(\mathrm{d})$ & 51 & 51 & 47 & 43 & 36 & 64 & 64 and 176 \\
\hline Age at postmortem (d) & 58 & 58 & 54 & 71 & 92 & 148 & 183 \\
\hline Interval treatment-postmortem (d) & 7 & 7 & 7 & 28 & 56 & 84 & 7 and 119 \\
\hline \multicolumn{8}{|l|}{ Dose of rh4S ( $\mu \mathrm{g}$ per joint $) \S$} \\
\hline \multicolumn{8}{|l|}{ Knee } \\
\hline Left & 0 & 0 & 1 & 0 & 0 & 0 & 0 \\
\hline Right & 10 & 100 & 500 & 500 & 500 & 500 & 500 \\
\hline \multicolumn{8}{|l|}{ Elbow } \\
\hline Left & 0 & 0 & 1 & 0 & 0 & 0 & 0 \\
\hline Right & 10 & 100 & 500 & 500 & 500 & 500 & 500 \\
\hline
\end{tabular}

* IA INJ with rh4S or buffer.

** Same dose administered twice in same joints.

$\S$ Volume injected in each joint was $70 \mu \mathrm{L}(0 \mu \mathrm{g}$ per joint $=70 \mu \mathrm{L}$ of buffer $)$. 
paraformaldehyde $/ 0.7 \%(\mathrm{vol} / \mathrm{vol})$ ruthenium hexamine trichloride in $0.1 \mathrm{M}$ cacodylate buffer ( $\mathrm{pH}$ 7.2) and embedded in Spurr's resin. Toluidine bluestained sections $(1 \mu \mathrm{m})$ were evaluated for clearance of lysosomal contents in chondrocytes (see below). Thin sections $(60-80 \mathrm{~nm})$ were stained with $7 \%$ uranyl acetate and viewed on a Philips CM100 electron microscope. Anterior and posterior cruciate ligaments and synovium samples were similarly processed for TEM.

Depth of clearance of lysosomal contents in chondrocytes. Sections were examined using a $10 \mathrm{~mm} \times 10 \mathrm{~mm}$ grid on an Olympus microscope eyepiece. The absolute depth of penetration of rh $4 \mathrm{~S}$ from the articular surface was determined by recording the depth to which chondrocytes were free of lysosomal vacuolation. Relative depth of clearance was then calculated as a percentage of total cartilage thickness (measured as the distance from articular surface to subchondral bone). Because total cartilage thickness varies across the joint, particularly in the knee, measurements were taken at both the thickest and thinnest part of the section.

\section{RESULTS}

In vitro correction of cartilage tissue. An initial in vitro study was undertaken to determine whether high levels of rh4S added to cell culture medium could affect chondrocyte GAG storage. MPS VI cartilage tissue was cultured in vitro for a total of $4 \mathrm{~d}$ in the presence of $0.5,5.0$, or $50 \mu \mathrm{g} / \mathrm{mL} \mathrm{rh} 4 \mathrm{~S}$. No change in chondrocyte vacuolation was observed at any of the doses tested, indicating that the exogenous enzyme had not been taken up by cells (Fig. 1).

In vivo correction of cartilage and surrounding tissues. The IA INJ of buffer alone $7 \mathrm{~d}$ before analysis had no effect on lysosomal storage in chondrocytes and maximal storage was observed throughout the full cartilage thickness (Fig. 2, A, C, $E$, and $G)$. Joints injected with either rf $4 \mathrm{~S}$ or rh4S exhibited clearance of stored lysosomal GAG from some but not all chondrocytes $7 \mathrm{~d}$ post injection (Fig. 2, $B, D, F$, and $H$ ). Clearance was observed with doses of $10 \mu \mathrm{g}, 100 \mu \mathrm{g}$, or 500 $\mu \mathrm{g}$ of rh $4 \mathrm{~S}$, whereas negligible change was observed in joints treated with $1 \mu \mathrm{g}$ rh4S. Chondrocytes located nearer the articular surface, i.e. closest to the source of exogenous rh $4 \mathrm{~S}$, were cleared preferentially of storage material. Chondrocytes adjacent to subchondral bone were not affected by rh $4 \mathrm{~S}$ administration at any dose. The interface where correction ended was well demarcated (Fig. 2B). The percentage of total cartilage thickness in which the resident chondrocytes showed clearance of storage correlated with the dose of rh4S administered (Fig. 3, A-C). No apparent difference was observed in the ability of recombinant human or feline $4 \mathrm{~S}$ to degrade stored GAG. IA INJ also resulted in the removal of stored GAG from cruciate ligament cells (Fig. 4, $A$ and $B$ ) and synoviocytes (Fig. 4, $C$ and $D$ ).

One month after IA INJ with $500 \mu \mathrm{g}$ of rh4S, a small amount of reaccumulation of lysosomal storage material had

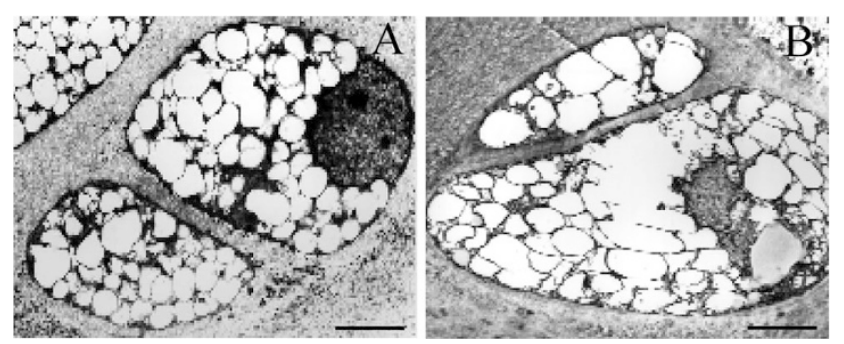

Figure 1. In vitro correction of chondrocytes. TEM of cartilage chondrocytes from cartilage tissue incubated for $5 \mathrm{~d}$ in cell culture $(A)$ and cartilage tissue incubated for $5 \mathrm{~d}$ in the presence of $5.0 \mu \mathrm{g} / \mathrm{mL} \mathrm{rh} 4 \mathrm{~S}(B)$. Bar $=5 \mu \mathrm{m}$.

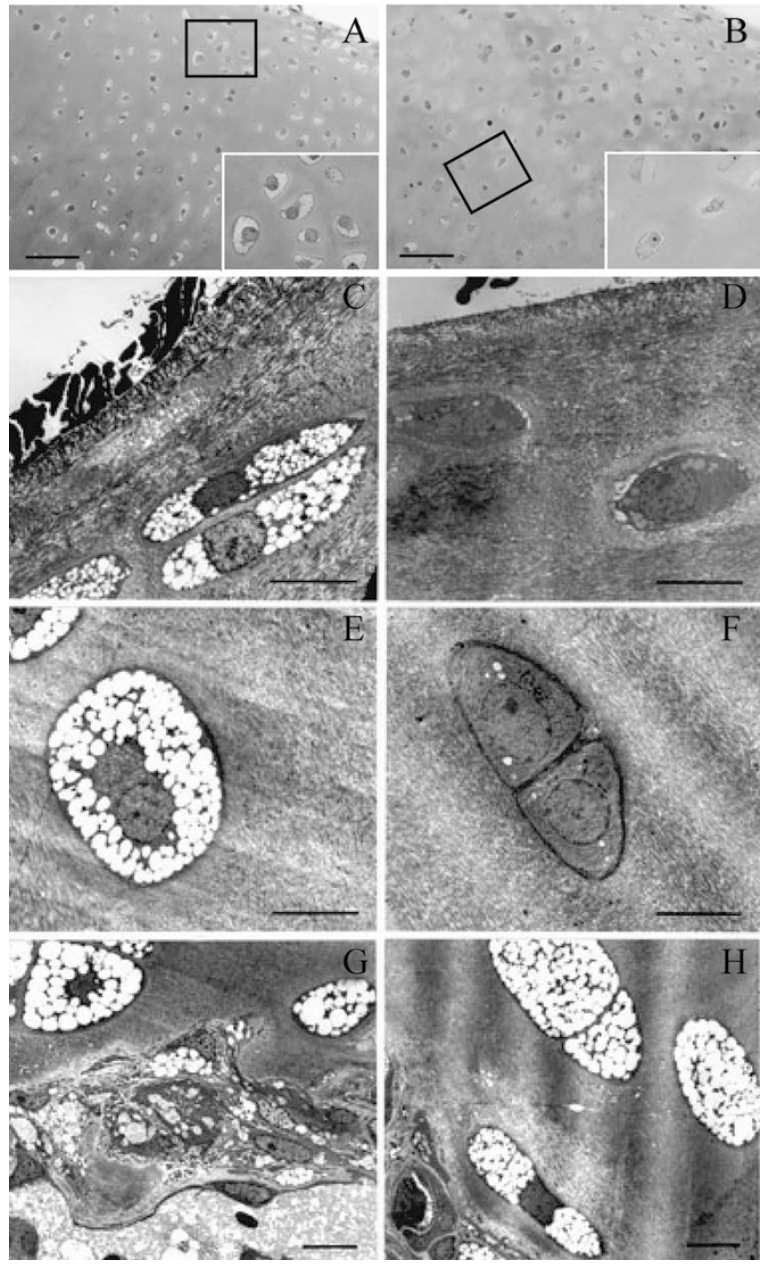

Figure 2. Chondrocyte response to IA INJ of recombinant enzyme. Toluidine blue-stained sections of cartilage receiving buffer $(A)$ or $500 \mu \mathrm{g}$ rh $4 \mathrm{~S}(B), 7 \mathrm{~d}$ after injection $(200 \times$; bar $=50 \mu \mathrm{m})$. Insert $=1000 \times$ magnification of indicated area in $(A)$ representing vacuolated chondrocytes or the interface where lysosomal clearance ends $(B)$. TEM of chondrocytes from the tibial plateau at the surface $(C, D)$, mid-depth $(E, F)$, and adjacent to the subchondral bone $(G, H)$ from a knee joint receiving buffer alone $(C, E, G)$ or $100 \mu \mathrm{g}$ rf4S $(D, F, H) 7 \mathrm{~d}$ after injection (bar $=5 \mu \mathrm{m})$.

occurred within the chondrocytes located at the surface of the cartilage (Fig. 5A), however, cells deeper in the tissue were still free of vacuolation (Fig. $5 D$ ). Two and three months after IA INJ with $500 \mu \mathrm{g}$ of rh4S, reaccumulation of storage had occurred in all chondrocytes throughout the full thickness of cartilage and all cells contained large vacuoles (Fig. 3, $D-F$; Fig. 5, $B, C, E$, and $F$ ). The same result was observed in all joints.

The one MPS VI animal treated with two doses of rh4S on d 64 and d 176 also showed improvement in chondrocyte vacuolation (data not shown). This most likely reflected the effect of the second set of IA INJ given 1 wk before postmortem.

In the buffer-treated joints of MPS VI cats, synovial cells were hypertrophic (large and foamy) due to accumulation of GAG leading to widespread thickening of the synovium (Fig. $6, A$ and $B)$. The synovium also appeared hyperplastic. One week after a single IA INJ of rh4S (all doses), the level of storage in synovial cells was considerably reduced with the 
A

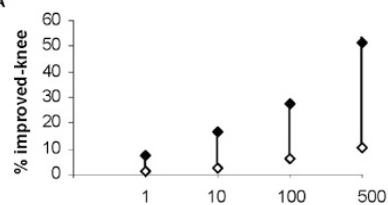

D

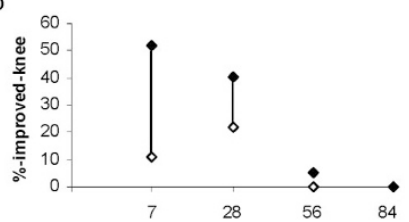

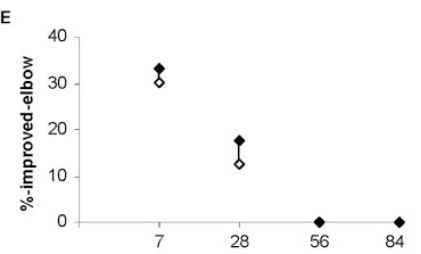
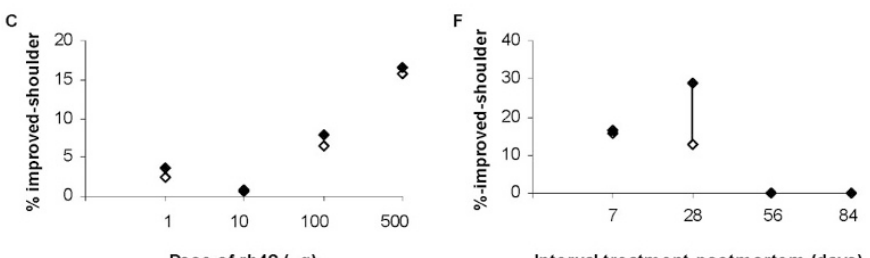

Interval treatment-postmortem (days)

Figure 3. Percentage correction in cartilage. Percentage of total cartilage thickness showing reduction in lysosomal vacuolation $7 \mathrm{~d}$ after a single IA INJ with rh4S, in the knee $(A)$, elbow $(B)$, and shoulder $(C)$ using different doses of rh4S ( $n=1$ per dose). Percentage of total cartilage thickness showing reduction in lysosomal vacuolation $7,28,56$, and $84 \mathrm{~d}$ after a single IA INJ of rh4S (500 $\mu \mathrm{g}$ per joint), in the knee $(D)$, elbow $(E)$, and shoulder $(F)(n=1$ per time point). For each sample, measurements were made at the thickest and thinnest areas of tissue; $(\diamond)$ represents the maximum value and ( ) represents the minimum value. NA, data not available.
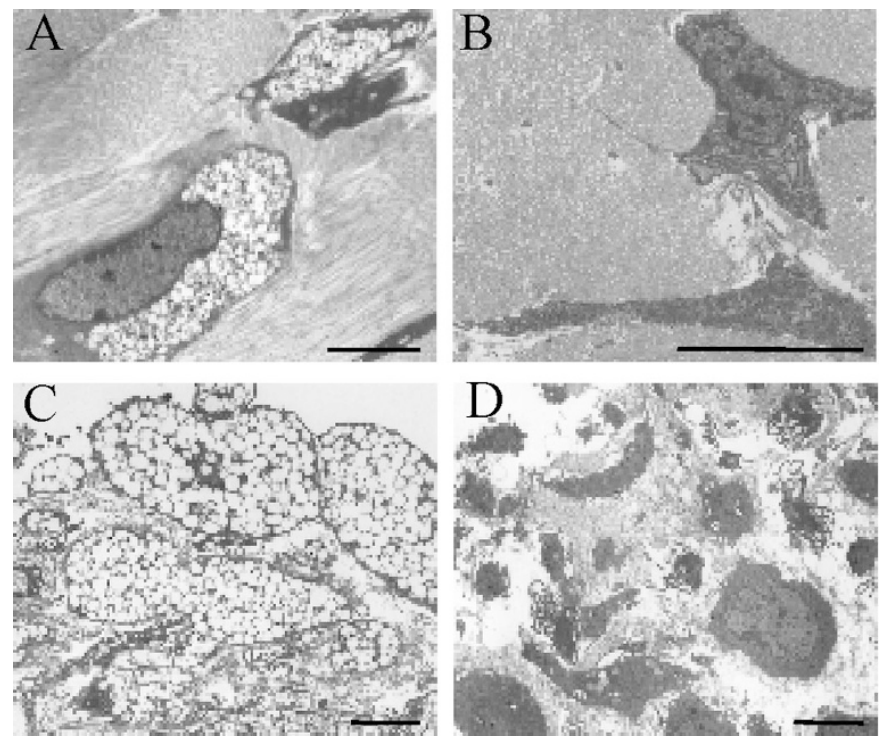

Figure 4. Ligament and synovial cell response to IA INJ of recombinant enzyme. TEM of anterior cruciate ligament from a knee joint receiving buffer alone $(A)$ or $100 \mu \mathrm{g}$ rf4S $(B)$ and synovial membrane from the same animal in knee receiving buffer alone $(C)$ or $100 \mu \mathrm{g} r 4 \mathrm{~S}(D)$. Bar $=5 \mu \mathrm{m}$.

majority of cells appearing smaller and less foamy (Fig. 6, C and $D$ ). As a result of this, the overall thickness of the synovium was reduced, however, this was not uniform across the joint. No obvious difference in hyperplasia was observed. Reaccumulation of storage material within synovial cells was

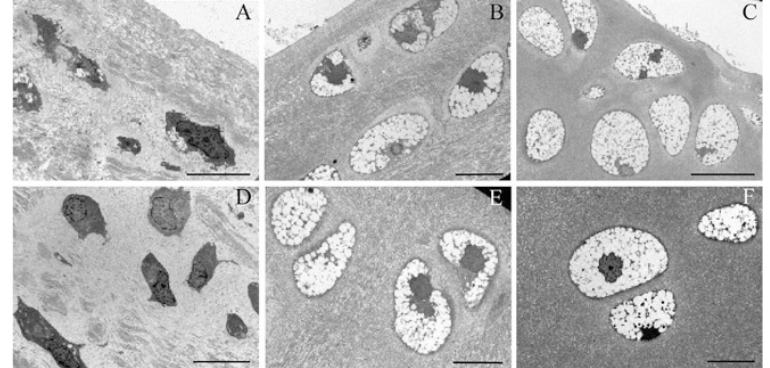

Figure 5. Reaccumulation of storage material in chondrocytes. Chondrocytes from the tibial plateau of a knee joint receiving $500 \mu \mathrm{g} \operatorname{rh} 4 \mathrm{~S}, 1$ mo $(A, D), 2$ mo $(B, E)$, or 3 mo $(C, F)$ after IA INJ. Surface cells $(A, B, C)$, mid-depth chondrocytes $(D, E, F)$. Bar $=10 \mu \mathrm{m}$.

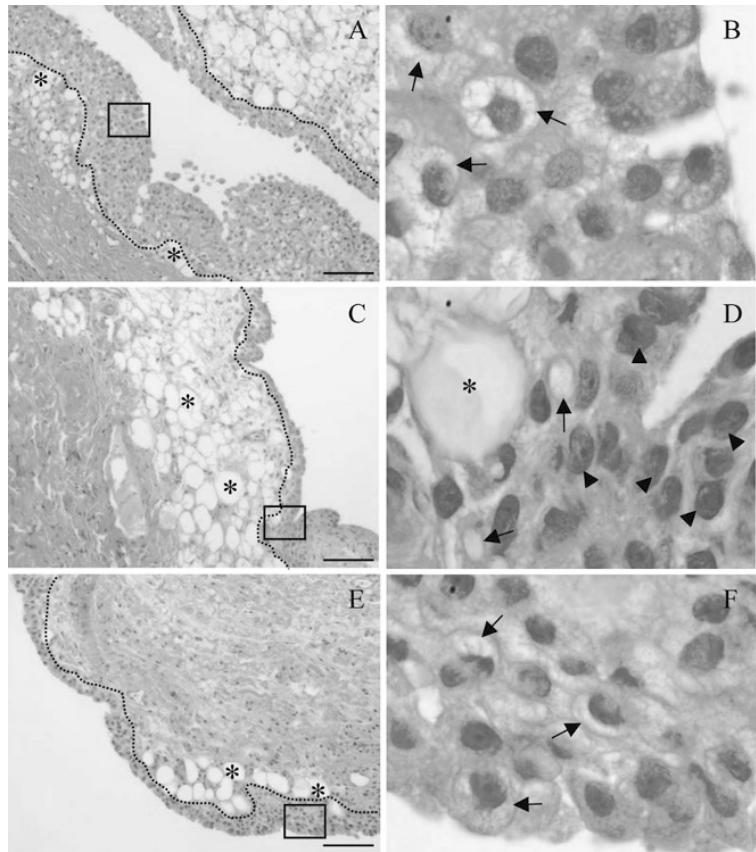

Figure 6. Synovial response to IA INJ of recombinant enzyme. Synovium from a buffer-treated joint $(A)$, a joint treated with $500 \mu \mathrm{g}$ rh $4 \mathrm{~S} 7 \mathrm{~d}$ after injection $(C)$ or $1 \mathrm{mo}$ after injection $(E), 100 \times$ magnification. Bar $=100 \mu \mathrm{m}$, dotted line denotes limit of synovial lining cells. Higher magnification (1000×) of rectangle area in $A, C$, and $E$ is shown in $B, D$, and $F$, respectively. Arrowheads indicate corrected cells. Arrows indicate cells containing storage material. Fat cells $(*)$ are identified by their large size and empty appearance.

observed 1 mo after a single injection of $500 \mu \mathrm{g}$ rh4S, with cells appearing mild or moderately foamy (Fig. 6, $E$ and $F$ ). Synovial thickness still appeared reduced. Two and three months after a single injection of rh $4 \mathrm{~S}$, the appearance of the synovium was similar to that observed in the buffer-treated joints, with widespread vacuolation in cells and a thickened, hyperplastic synovium (data not shown). No signs of inflammation were detected in any control or treated joint.

Most cells observed on the smears of synovial fluid collected from buffer-treated and rh4S-treated joints of MPS VI cats were synoviocyte-like cells (data not shown). Some of these cells appeared vacuolated. None of the smears examined suggested signs of inflammation.

General health. No abnormalities were observed during or in the hours after the IA INJ in any of the treated cats. All cats recovered well from the anesthesia and were able to stand and 
walk when awake. No signs of inflammation were detected during the days that followed the IA INJ. Appetite and level of activity were not affected by the procedure. No abnormalities within buffer-treated or rh4S-treated joints were detected at postmortem. No signs of inflammation were observed in any joint.

\section{DISCUSSION}

A single dose of rh $4 \mathrm{~S}$ injected directly into the intraarticular joint space of shoulders, elbows, and knees of young MPS VI cats resulted in a clear decrease in lysosomal storage within chondrocytes after $7 \mathrm{~d}$. The correction of lysosomal storage was dose dependent and could be achieved up to approximately mid-depth from the articular surface of cartilage with a dose of $500 \mu \mathrm{g}$ per joint. A decrease in cell vacuolation was also detectable in the synovium of all rh4S-treated joints for up to a month after IA INJ (and in ligament cells after $7 \mathrm{~d}$ ). This indicates that synoviocytes and chondrocytes (as well as ligament cells) possess the appropriate receptors for $\mathrm{rh} 4 \mathrm{~S}$ uptake and that translocation of the enzyme to the lysosome occurs in vivo. Mannose-6-phosphate-receptor mediated uptake of exogenous $4 \mathrm{~S}$ into chondrocytes and subsequent degradation of stored lysosomal GAG has been previously demonstrated in vitro $(21,22)$.

These results indicate that a major obstacle to joint therapy using intravenous ERT is diffusion of enzyme through the synovium surrounding joints. The tight compartmentalization of the joint space as well as the rapid uptake of enzyme by major organs such as the liver (21) significantly reduces the efficacy of intravenous ERT to articular chondrocytes. The architecture of MPS VI synovial membrane appears considerably disrupted due to the presence of excessive vacuolation within synoviocytes and marked synovial hyperplasia. Because one of the primary functions of synovium is to supply nutrients to avascular cartilage, the characteristic synovial microvasculature needs to be preserved as well as the arrangement of its superficial cellular layer (23). Therefore, if the synovial architecture is sufficiently disrupted in MPS VI joints, alteration in synovial fluid turnover may occur with possible reduction in availability of nutrients for the chondrocytes. This hypothesis is indirectly supported by the fact that a higher percentage of ${ }^{3} \mathrm{H}-4 \mathrm{~S}$ (administered intravenously) is measured in the articular cartilage of a normal cat than in the cartilage of a MPS VI cat (21). An additional confounding characteristic is the marked increase in cartilage thickness in MPS VI, which must be traversed before enzyme can reach its target cells. It is generally accepted that high levels of circulating drugs must be administered to achieve therapeutic levels in synovial joints (24). The hyperplasia of both synovium and cartilage observed in MPS VI add to this problem of accessibility.

Other roles for synovial lining cells include the synthesis of joint lubricant, matrix molecules, digestive enzymes, and cytokines, as well as participation in immunologic processes (25). Changes in composition of the synovial fluid have been recognized in MPS VII dogs (26). Finally, the 4 S requirement of the synovial membrane may be very high (i.e. high GAG turnover) and very little of the intravenously administered enzyme may remain for penetration into articular cartilage after passage through the synovium. Indeed, rh4S was undetectable in articular cartilage of MPS VI cats treated with long-term rh4S ERT (17).

Chondrocytes possess the appropriate mannose-6-phosphate receptors for internalization of the recombinant precursor form of $4 \mathrm{~S}(21,22)$. When removed from their surrounding extracellular matrix and grown in monolayer culture, exogenous enzyme is correctly targeted to the lysosome where it degrades stored GAG. In this study, despite the addition of high levels of rh4S (at levels higher than that achievable in vivo) to the culture medium, no alteration in chondrocyte vacuolation was observed within cartilage tissue where the extracellular matrix was preserved. In contrast, the addition of rh4S directly into the joint space in vivo resulted in a clear resolution of GAG storage in chondrocytes that was dose dependent, favoring chondrocytes located nearer the articular surface. The penetration of $4 \mathrm{~S}$ into cartilage tissue in vivo compared with the lack of penetration into cartilage tissue in vitro is most likely a consequence of the biomechanical forces acting upon the joint driving diffusion through the cartilage tissue.

No apparent difference was observed between $\mathrm{rf} 4 \mathrm{~S}$ and $\mathrm{rh} 4 \mathrm{~S}$ in ability to degrade accumulated GAG in vivo. However, neither enzyme preparation was capable of penetrating cartilage to the deepest level adjacent to subchondral bone. It is possible that by increasing the dose beyond that assessed here, enzyme will be accessible to cells deeper in the cartilage tissue. From the present in vitro results, it is apparent that the application of biomechanical forces on cartilage tissue is important for diffusion through the extracellular matrix. Articular cartilage acts to diffuse the pressure impinging on the cartilage surface at the point of loading impact into surrounding cartilage tissue to protect the underlying bone from high pressure (27). With increasing depth away from the articular surface, the force applied may be diffused to such an extent that it can no longer promote diffusion of the $4 \mathrm{~S}$ molecule through the cartilage extracellular matrix.

The reaccumulation of storage was observed in chondrocytes at the articular surface earlier than in deeper region cells and reflects the intrinsic metabolic differences observed in different subpopulations of articular chondrocytes. Higher amounts of DS-containing proteoglycans are found at the cartilage surface (28) and cells in this region degrade proteoglycan more rapidly (29). Although the latter observation concerns predominantly nonlysosomal proteoglycan turnover, it is likely that the lysosomal system is also more active in these cells. Thus, surface chondrocytes are more metabolically active and have more DS GAG to digest than other articular chondrocytes leading to the more rapid reaccumulation of GAG after a single dose of replacement enzyme.

Overall, our data indicate that by using IA INJ of rh4S, we can achieve a high concentration of $4 \mathrm{~S}$ locally and, as a consequence, gain direct benefits for chondrocytes, ligament cells, and synoviocytes. Our data also suggest that a monthly interval for the IA INJ could be sufficient to achieve considerable improvement within joint tissues and prevent the de- 
velopment of DJD in MPS VI cats. The fact that no inflammatory reaction was observed after repeated IA INJ in one MPS VI cat represents a very encouraging result and will require more study.

IA therapy with rh $4 \mathrm{~S}$ is one approach that will have merits when combined with other approaches such as intravenous ERT. As it will not be feasible to inject all joints, major weight bearing joints will undoubtedly be selected for therapy. Because cartilage is very difficult to repair once damaged, IA therapy will ideally be initiated well before the development of irreversible lesions in cartilage. A complementary therapeutic option targeting joint tissues, including IA therapy with rh4S, might prove beneficial if available to MPS VI patients.

Acknowledgments. The authors thank Prof. Mark Haskins, University of Pennsylvania, for the original heterozygous MPS VI cats; the animal care staff at the Institute of Medical and Veterinary Science for daily care of the cat colony; Ms. Lyn Waterhouse (Adelaide Microscopy, University of Adelaide) for TEM; and Dr. John W. Finnie (Veterinary Services Division, Institute of Medical and Veterinary Science) for regular histopathology assessments. We also thank Dr. Stuart Swiedler and Dr. Charles A. O'Neill, BioMarin Pharmaceutical Inc., for their regular support and input.

\section{REFERENCES}

1. Neufeld EF, Muenzer J 2001 The mucopolysaccharidoses. In: Scriver, CR, Beaudet, AL, Sly WS, Valle D (eds) The Metabolic and Molecular Basis of Inherited Disease. McGraw-Hill, New York, pp 3421-3452

2. Pilz H, von Figura K, Goebel HH 1979 Deficiency of arylsulfatase B in 2 brothers aged 40 and 38 years (Maroteaux-Lamy Syndrome, type B). Ann Neurol 6:315-325

3. Spranger JW, Koch F, McKusick VA, Natzschka J, Wiedemann HR, Zellweger H 1970 Mucopolysaccharidosis VI (Maroteaux-Lamy's disease). Helv Paediatr Acta 25:337-362

4. Keller C, Briner J, Schneider J, Spycher M, Rampini S, Gitzelmann R 1987 [Mucopolysaccharidosis 6-A (Maroteaux-Lamy disease): comparison of clinical and pathologico-anatomic findings in a 27-year-old patient.] Helv Paediatr Acta 42:317333

5. Crawley AC, Niedzielski KH, Isaac EL, Davey RC, Byers S, Hopwood JJ 1997 Enzyme replacement therapy from birth in a feline model of mucopolysaccharidosis type VI. J Clin Invest 99:651-662

6. Crawley AC, Yogalingam G, Muller VJ, Hopwood JJ 1998 Two mutations within a feline mucopolysaccharidosis type VI colony cause three different clinical phenotypes. J Clin Invest 101:109-119

7. Haskins ME, Jezyk PF, Patterson DF 1979 Mucopolysaccharid storage disease in three families of cats with arylsulfatase B deficiency: leukocyte studies and carrier identification. Pediatr Res 13:1203-1210

8. Konde LJ, Thrall MA, Gasper P, Dial SM, McBiles K, Colgan S, Haskins M 1987 Radiographically visualized skeletal changes associated with mucopolysaccharidosis VI in cats. Vet Radiol 28:223-228
9. Crawley AC, Brooks DA, Muller VJ, Petersen BA, Isaac EL, Bielicki J, King BM, Boulter CD, Moore AJ, Fazzalari NL, Anson DS, Byers S, Hopwood JJ 1996 Enzyme replacement therapy in a feline model of Maroteaux-Lamy syndrome. J Clin Invest 97:1864-1873

10. Haskins ME, Aguirre GD, Jezyk PF, Patterson DF 1980 Pathology of the feline model of mucopolysaccharidosis VI. Am J Pathol 101:657-674

11. Simonaro CM, Haskins ME, Schuchman EH 2001 Articular chondrocytes from animals with dermatan sulfate storage disease undergo a high rate of apoptosis and release nitric oxide and inflammatory cytokines: a possible mechanism underlying degenerative joint disease in the mucopolysaccharidoses. Lab Invest 81:1319-1328

12. Simonaro CM, D'Angelo, M, Haskins ME, Schuchman EH 2005 Joint and bone disease in mucopolysaccharidoses VI and VII: identification of new therapeutic targets and biomarkers using animal models. Pediatr Res 57:701-707

13. Krivit W 2002 Stem cell bone marrow transplantation in patients with metabolic storage diseases. Adv Pediatr 49:359-378

14. Herskhovitz E, Young E, Rainer J, Hall CM, Lidchi V, Chong K, Vellodi A 1999 Bone marrow transplantation for Maroteaux-Lamy syndrome (MPS VI): long term follow up. J Inherit Metab Dis 22:50-62

15. Harmatz P, Whitley CB, Waber L, Pais R, Steiner R, Plecko B, Kaplan P, Simon J, Butensky E, Hopwood JJ 2004 Enzyme replacement therapy in mucopolysaccharidosis VI (Maroteaux-Lamy syndrome). J Pediatr 144:574-580

16. Byers S, Nuttall JD, Crawley AC, Hopwood JJ, Smith K, Fazzalari NL 1997 Effect of enzyme replacement therapy on bone formation in a feline model of mucopolysaccharidosis type VI. Bone 21:425-431

17. Auclair D, Hopwood JJ, Brooks DA, Lemontt JF, Crawley AC 2003 Replacement therapy in mucopolysaccharidosis type VI: advantages of early onset of therapy. Mol Gen Metab 78:163-174

18. Yogalingam G, Litjens T, Bielicki J, Crawley AC, Muller V, Anson DS, Hopwood JJ 1996 Feline mucopolysaccharidosis Type VI. Characterization of recombinant $\mathrm{N}$-acetylgalactosamine 4-sulfatase and identification of a mutation causing the disease. J Biol Chem 271:27259-27265

19. Gibson GJ, Saccone GT, Brooks DA, Clements PR, Hopwood JJ 1987 Human $\mathrm{N}$-acetylgalactosamine-4-sulphate sulphatase. Purification, monoclonal antibody production and native and subunit Mr values. Biochem J 248:755-764

20. Bradford MM 1976 A rapid and sensitive method for the quantitation of microgram quantities of protein utilizing the principle of protein-dye binding. Anal Biochem $72: 248-254$

21. Byers S, Crawley AC, Brumfield LK, Nuttall JD, Hopwood JJ 2000 Enzyme replacement therapy in feline model of MPS VI: modification of enzyme structure and dose frequency. Pediatr Res 47:743-749

22. Fillat C, Simonaro CM, Yeyati PL, Abkowitz JL, Haskins ME, Schuchman EH 1996 Arylsulfatase B activities and glycosaminoglycan levels in retrovirally transduced mucopolysaccharidosis type VI cells. Prospect for gene therapy. J Clin Invest 98:497-502

23. Levick JR 1995 Microvascular architecture and exchange in synovial joints. Microcirculation 2:217-233

24. Evans CH, Robbins PD 1994 Gene therapy for arthritis. In: Wolff, JA (ed) Gene Therapeutics: Methods and Applications of Direct Gene Transfer. Birkhauser, Boston, pp 320-344

25. Allan D 1998 Structure and physiology of joints and their relationship to repetitive strain injuries. Clin Orthop Relat Res 351:32-38

26. Volk SW, Kapatkin AS, Haskins ME, Walton RM, D'Angelo, M 2003 Gelatinase activity in synovial fluid and synovium obtained from healthy and osteoarthritic joints of dogs. Am J Vet Res 64:1225-1233

27. Shrive NG, O'Connor, JJ, Goodfellow JW 1978 Load-bearing in the knee joint. Clin Orthop Relat Res 131:279-287

28. Poole AR, Webber C, Pidoux I, Choi H, Rosenberg LC 1986 Localization of a dermatan sulfate proteoglycan (DS-PGII) in cartilage and the presence of an immunologically related species in other tissues. J Histochem Cytochem 34:619-625

29. Aydelotte MB, Greenhill RR, Kuettner KE 1988 Differences between subpopulations of cultured bovine articular chondrocytes. II. Proteoglycan metabolism. Connect Tissue Res 18:223-234 